\title{
Conhecimento de pediatras e nutricionistas sobre o tratamento da alergia ao leite de vaca no lactente
}

\author{
Pediatricians and nutritionists knowledge about treatment of cow milk allergy in infants
}

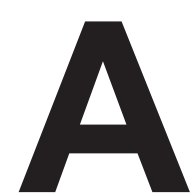
alergia alimentar tem sido detectada com maior freqüência nos últimos anos, tanto na população pediátrica como em adultos. Alguns autores estimam que a prevalência de alergia alimentar seja de quase $6 \%$ em crianças menores de três anos de idade e, entre 3 e $4 \%$, na população em geral. A entidade é atualmente considerada um problema de saúde pública pelo impacto médico, financeiro e social para as crianças acometidas e seus familiares ${ }^{(1)}$.

O único tratamento preconizado até o momento para as alergias alimentares é a restrição absoluta do alimento responsável da dieta do paciente. A base do mesmo consiste essencialmente em dois aspectos: exclusão dos alérgenos alimentares e utilização de fórmulas ou dietas hipoalergênicas ${ }^{(2)}$.

O objetivo final do tratamento nutricional é proporcionar à criança crescimento e desenvolvimento adequados, sendo necessário para tal o controle dos sintomas alérgicos e da progressão da doença.

Na maior parte dos serviços pediátricos, o acompanhamento da alergia alimentar é sistematicamente realizado por equipe multiprofissional. Nesse atendimento, avalia-se a evolução do quadro alérgico e monitorizam-se os parâmetros nutricionais. A orientação básica consiste na reposição adequada do alimento excluído, para que não ocorram prejuízos ao crescimento e desenvolvimento do paciente ${ }^{(3)}$.

É aconselhável que o pediatra e/ou o nutricionista incluam na anamnese a avaliação da ingestão alimentar por meio do dia alimentar habitual, do recordatório de 24 horas e/ou da freqüência de consumo. O inquérito permite observar se ocorreu exclusão completa da proteína alergênica, avaliar a adequação das fórmulas de substituição e garantir que os nutrientes atinjam as recomendações nutricionais, evitando-se assim comprometimento pôndero-estatural e outras carências ${ }^{(4)}$.

O estudo de Cortez et a/(5) constitui o primeiro inquérito em nível nacional que avalia o conhecimento de pediatras e nutricionistas a respeito das dietas de substituição para casos de lactentes com alergia à proteína do leite de vaca. Observou-se ainda a aferição do valor calórico da dieta empregada, a utilização de algum padrão de referência e o conhecimento a respeito das necessidades diárias de cálcio. A quase totalidade dos profissionais que participaram do estudo possuía adequado grau de especialização, muitos com mestrado e doutorado. Apenas metade dos profissionais preocupou-se em realizar algum cálculo de ingestão calórica e menor parcela ainda utilizou algum padrão de referência.

Os dados acima citados são motivos de preocupação, pois há risco dos lactentes serem submetidos a dietas inadequadas, que podem determinar comprometimento do estado nutricional e carências nutricionais específicas, tais como: menor ingestão proteínas, lipídios, cálcio, fósforo, vitamina $\mathrm{D}$ e outros micronutrientes ${ }^{(6)}$.

A Academia Americana de Pediatria (AAP) considera como fórmula hipoalergênica aquela que não causa reações alérgicas em até $90 \%$ das crianças com alergia ao leite de vaca, comprovação esta realizada com testes de provocação duplo-cegos e controlados com placebo, em estudos prospectivos e randomizados. Não são recomendadas as fórmulas parcialmente hidrolisadas, por conterem proteínas intactas do leite de vaca e, portanto, com potencial alergênico. Neste sentido, o trabalho de Cortez et $a^{(5)}$ aponta percentual muito pequeno de pediatras e nutricionistas que afirmaram utilizar as fórmulas hipoalergênicas como alternativas nutricionais em crianças portadoras de alergia à proteína do leite de vaca..

Os pediatras, em parcela maior que os nutricionistas, cometem erros conceituais ao utilizarem fórmulas à base de proteína do leite de vaca sem lactose para os casos de alergia alimentar, assim como utilizam o leite de cabra como alimento substitutivo. Aproximadamente $50 \%$ dos integrantes da pesquisa prescrevem os preparados à base do extrato de soja em apresentações líquidas ou em pó(5). Deve-se realçar que as mesmas não atendem às recomendações nutricionais a para faixa etária ${ }^{(7)}$.

As fórmulas atualmente disponíveis no mercado adequadas para crianças menores de um ano e que podem ter indicação no manejo dietético da alergia à proteína do leite de vaca são: 
1. Fórmulas à base de proteína isolada de soja, com proteínas purificadas e suplementadas para atingir às recomendações nutricionais do lactente.

2. Fórmulas à base de proteína extensamente hidrolisada (hidrolisados protéicos), compostas por peptídeos, sobretudo, e aminoácidos obtidos por hidrólise enzimática e/ou térmica ou por ultrafiltragem.

3. Fórmulas de aminoácidos, as únicas consideradas totalmente não alergênicas.

As fórmulas à base de proteína isolada de soja foram as mais indicadas no estudo publicado a seguir(5), como alternativa nutricional para os casos de alergia à proteína do leite de vaca. Há, na literatura, várias restrições ao uso das mesmas nos casos não lgE mediados, não sendo recomendadas na terapia nutricional de lactentes tanto pela Sociedade Européia de Alergologia Pediátrica e Imunologia Clínica (Espaci), quanto pela Sociedade Européia de Gastroenterologia, Hepatologia e Nutrição Pediátrica (ESPGHAN). A AAP sugere considerar o uso de tal fórmula nas alergias mediadas por $\mathrm{lgE}$, em lactentes acima de seis meses ${ }^{(8,9)}$.

Nas hipersensibilidades não mediadas por $\lg E$ e que apresentam manifestações como colites, enterocolites ou esofagites, o risco de alergia simultânea à soja pode chegar a $60 \%$, não sendo, portanto, rotineiramente recomendado o seu emprego, exceto em formas clínicas leves ou nas fases mais tardias de tratamento em algumas situações, após, no mínimo, seis a oito semanas de uso de fórmulas à base de proteína extensamente hidrolisada ou à base de aminoácidos.

É interessante frisar que, no estudo de Cortez

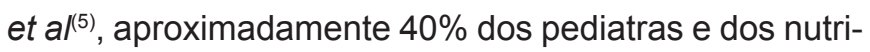
cionistas não apontaram as fórmulas à base de aminoá- cidos como a melhor alternativa dietética, especialmente nos casos mais complexos e graves. Esses dados indicam que os profissionais da saúde do nosso meio necessitam ainda de informações adicionais quanto aos conceitos fisiopatológicos da alergia à proteína do leite de vaca, assim como de informações complementares quanto às alternativas nutricionais no manuseio dos lactentes acometidos.

\section{Mauro Sérgio Toporovski ${ }^{1}$}

\section{Referências bibliográficas}

1. Marklund B, Ahlstedt S, Nordstrom G. Health-related quality of life in food hypersensitive schoolchildren and their families: parents' perceptions. Health Qual Life Outcomes 2006;4:48.

2. Sampson HA. Food allergy - accurately identifying clinical reactivity. Allergy 2005;60:S19-24.

3. ExI BM, Deland U, Secretin MC, Preysch U, Wall M, Shmerling DH. Improved general health status in an unselected infant population following an allergen reduced dietary intervention programme: the ZUFF study programme. Part I; study design and 6 month nutritional behaviour. Eur J Nutr 2000;39:89-102.

4. Medeiros LCS, Speridião PGL, Sdepanian VL, Fagundes-Neto U, Morais MB. Ingestão de nutrientes e estado nutricional de crianças em dieta isenta de leite de vaca e derivados. J Pediatr (Rio J) 2004;80:363-70.

5. Cortez APB, Medeiros LCS, Speridião PGL, Fagundes-Neto U, Morais MB. Conhecimentos de pediatras e nutricionistas sobre o tratamento da alergia ao leite de vaca no lactente. Rev Paulista Pediatr 2007;25:106-13.

6. Zeiger RS. Dietary aspects of food allergy prevention in infants and children. J Pediatr Gastroenterol Nutr 2000;30:S77-86.

7. Castro APBM, Jacob CMA, Corradi GA, Abdalla D, Golçalves RFF, Rocha FTL et al. Evolução clínica e laboratorial de crianças com alergia a leite de vaca e ingestão de bebida à base de soja. Rev Paul Pediatr 2005;23:27-34

8. Host A, Koletzko B, Dreborg S, Muraro A, Wahn U, Aggett P et al. Dietary products used in infants for treatment and prevention of food allergy. Joint Statement of the European Society for Paediatric Allergology and Clinical Immunology (ESPACI) Committee on Hypoallergenic Formulas and the European Society for Paediatric Gastroenterology, Hepatology and Nutrition (ESPGHAN) Committee on Nutrition. Arch Dis Child.1999;81:80-4.

9. Giampietro PG, Kjellman NI, Oldaeus G, Woulters-Wesseling W, Businco L. Hypoallergenicity of an extensively hydrolyzed whey formula. Pediatr Allergy Immunol 2001;12:83-6.
'Professor doutor responsável pela disciplina de Gastroenterologia Pediátrica da Faculdade de Ciências Médicas da Santa Casa de São Paulo e presidente do Departamento de Gastroenterologia da Sociedade de Pediatria de São Paulo (SPSP)
Endereço para correspondência:

Mauro Sérgio Toporovski

Rua Joazeiro, 152

CEP 01253-030 - São Paulo/SP

E-mail: toporovski@uol.com.br

Recebido em: 23/4/2007 